\title{
Rosinified Phenolic Polyurethane as Surface Coatings
}

\author{
M. PATEL BHAUMIK and S. PATEL HASMUKH* \\ Department of Chemistry, Vallabh Vidhayanagar, Sardar Patel University, \\ Vallabh Vidhayanagar - 388 120, Gujarat, India \\ bhaumik_patel29@yahoo.co.in
}

Received 9 April 2014 / Accepted 2 May 2014

\begin{abstract}
New novel surface coating formulations were prepared by blending of rosinified phenolic resin with castor oil of different \% weight ratio was carried out. Thus obtained polyols were treated stoichiometrically with isophorone diisocyanate (IPDI) and toluene diisocyanate (TDI) to affoard polyurethane syrups. FT-IR analyses were monitoring for these polyurethane. These produced polyurethane syrups (i.e. resins) resins were casted into film. The result of polyurethane film were characterized for surface drying time, tack-free time, mechanical properties like scratch, impact, pencil hardness, adhesion and flexibility. The chemical properties like acid, alkalies and solvent resistance of these coats have also been checked.
\end{abstract}

Keywords: Castor oil, Rosinified phenolic resin, Polyurethane, Polyol, Isophorone diisocyanate, Toluene diisocyanate, Coating, Blend

\section{Introduction}

As the first commercial synthetic resin, phenolic resin have been widely used as adhesives composites, moldings, coatings, industrial laminates, abrasive materials, foundry resin, friction materials and matrix materials due to their excellent flame resistance, dimensional stability and chemical resistance ${ }^{1}$. Phenolics are continued to have an important role in the coating industry because of their versatility, coatings properties, and reasonable price. However, phenolic resin is brittle and not very tough, like many other thermosetting resins. Thus, modification of phenolic is an important subject for its further application more pertinent to paints. Some research publications show that phenolic resins have been used in order to get the modified polyol for polyurethane formation ${ }^{2-4}$. However, the reports indicate that phenolics based polyurethane used as a composite, adhesive, foam, etc. ${ }^{5-16}$.

One of the most natural rosinified phenolic resins are used in printing inks, in oil lacquers and as additives to alkyd paints because good compatibility with natural oils in which they improve the drying and shine. It can be polymerized by cooking with vegetable oils to make phenolic paints with fast drying, good hardness and high gloss ${ }^{17}$.

Castor oil (CO) sometimes described as a triglycerides of ricinoleic acid, is one of the naturally occurring glyceride that approaches being a pure compound. Castor oil (CO) serves 
as raw material for the manufacturing of number of industrial utility products ${ }^{18-20}$. Castor oil known preliminary for its medicinal use as a cathartics, is now also used primarily as an industrial raw material for the manufacturing of industrial products used in coatings, urethane derivatives, surfactants, dispersant, cosmetics, textile and lubricants ${ }^{21,22}$.

Term polyurethane (PU) originally referred to coating system that utilized high reactivity of isocyanates for chemical hardening. Polyurethane (PU) chemistry is based on reaction of a diisocyanate with compounds containing an active hydrogen atom to produce urethane linkages. There are many compounds that contain active hydrogen like water, alcohol, amines, hydroxyl group, acids etc. Such kind of reaction occurs at room temperature or at slightly elevated temperature. Due to such high reactivity of isocyanates with variety of compounds, it is possible to formulate urethane coating systems with different compositions and methods of applications. Polyurethanes are most widely used in coating industry as they exhibit excellent abrasion resistance, toughness, low temperature flexibility, chemical and corrosion resistance properties $^{23}$ and wide range of mechanical strength. In continuation to our earlier work ${ }^{24}$ the present work is scanned in following scheme 1.

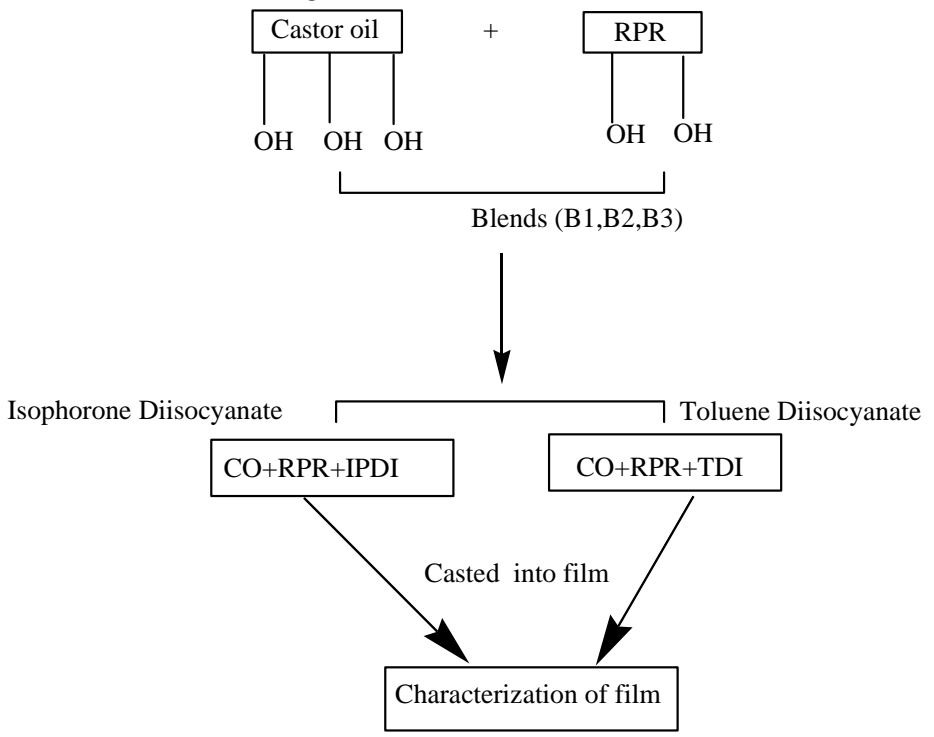

Scheme 1. Formation of polyurethane surface coatings

\section{Experimental}

Castor oil was purchased and Rosinified Phenolic Resin (RPR) were purchased from local market. Dibutyltin dilaurate (DBTDL) used as a catalyst, it was purchased from Himedia. Isophorone diisocyanate (IPDI) and Toluene diisocyanate (TDI) were purchased from the Bayer, (Dubai). Xylene used as a solvent was purchased from the S.d.fine chemical limited, (Mumbai). All other chemicals used were of pure grade.

\section{Blending of rosinified phenolic (RPR) resin and castor oil (CO)}

To prepare castor oil and rosinified phenolic resin blends, involving a physical mixing of both as described below: Three necked flask equipped with a mechanical stirrer, castor oil was charged and under continuous stirring desired amount of specific rosinified phenolic resin (as shown in Table 1) were added gradually over the period of half an hour. Upon the 
completion of addition the reaction mixture was stirred for an hour after which it was kept aside in a cylindrical glass container for overnight to check any tendency of separation of the two layers. In neither case separation of the two layers was observed. The physical properties of resultant above different percentage composition blends (RPR-CO) are given in Table 1.

Table 1. Composition of (RPR: CO) and Physical Properties

\begin{tabular}{ccccccc}
\hline S.No. & $\begin{array}{c}\text { Composition } \\
\text { RPR+CO }\end{array}$ & $\begin{array}{c}\text { OH Value } \\
\text { in mg of } \\
\text { KOH/g }\end{array}$ & $\begin{array}{c}\text { Acid } \\
\text { value }\end{array}$ & Colour & $\begin{array}{c}\text {-OH } \\
\text { Equivalent } \\
\text { Weight }\end{array}$ & $\begin{array}{c}\text { Moisture } \\
\text { content, } \\
\%\end{array}$ \\
\hline B1 & $40: 60$ & 115.82 & 8.40 & Pale yellow & 484.84 & 0.055 \\
B2 & $50: 50$ & 103.18 & 10.65 & Pale yellow & 543.47 & 0.065 \\
B3 & $60: 40$ & 90.36 & 12.30 & Pale yellow & 613.76 & 0.065 \\
\hline
\end{tabular}

\section{Synthesis of polyurethane}

Blends of RPR-CO were taken in three necked flask which was equipped with mechanical stirrer, reflux condenser and thermometer. The stoichiometric amounts of isophorone diisocyanate (IPDI) were also using Toluene diisocyanate (TDI) was added gradually in presence of dibutyltin dilaurate (DBTDL) catalyst. The reaction was performed at $50-65{ }^{\circ} \mathrm{C}$ with continuous stirring for 3-4 h. The prepolymer was isolated as a viscous liquid. As the reaction mix becomes pourable viscous liquid. It was poured in to the glass cavity. It was kept at room temperature for $24 \mathrm{~h}$ curing. These films were used for further study and characterization.

Table 2. PU Compositions Based on (RPR-CO) Blends for TDI and IPDI (Weight of Diisocynates $/ 10 \mathrm{~g}$ of polyol)

\begin{tabular}{cccccc}
\hline S. & Composition & \multicolumn{2}{c}{ IPDI } & \multicolumn{2}{c}{ TDI } \\
\cline { 3 - 6 } No. & RMP+CO & I1 & I2 & T1 & T1 \\
\hline 1. & $40: 60$ & 7.239 & 8.686 & 6.482 & 7.778 \\
2. & $50: 50$ & 6.375 & 7.650 & 5.710 & 6.852 \\
3. & $60: 40$ & 5.521 & 6.625 & 4.940 & 5.928 \\
\hline
\end{tabular}

\section{Panel preparation}

The mild steel panels were first degreased in alkali solution and subsequently swabbed with xylene to remove any type of oily material or contaminant from the surface. After xylene has been evaporated the panels were coated by the above prepared coating composition.

\section{Film characterization}

The coated panels were examined for drying time, adhesion test, flexibility test, scratch hardness, pencil hardness, impact resistance and chemical resistance properties by standard methods. The results are given in tables and respectively.

\section{Drying time}

The mild steel panels were used to determine the air drying time of films of various blends. The panels were prepared in a similar manner written above and coating compositions were applied. The films were checked for 'surface dry' and 'tack-free dry' stages at regular interval of time. The results of drying time determination are given in Table 3. 


\section{Adhesion test (ASTM D 3359)}

Adhesion of films were determined by employing cross-hatch adhesion test and panels for the test were prepared exactly in a similar manner to that of drying time determination test. Cross-hatch adhesion test was carried out after 168 hour of coating application. Adhesion test was carried out using reported method ${ }^{25}$. The results are given in Table 3.

Table 3. Properties of Films Prepared from PU Compositions Based on (RRP-CO)

Blends with TDI and IPDI

\begin{tabular}{ccccc}
\hline $\begin{array}{c}\text { Polyurethane } \\
\text { code }\end{array}$ & \multicolumn{2}{c}{ Drying time in minutes } & Adhesion & Flexibility \\
\hline B1PUI1 & 150 & 240 & $\mathrm{~F}$ & $\mathrm{P}$ \\
B2PUI1 & 145 & 235 & $\mathrm{P}$ & $\mathrm{P}$ \\
B3PUI1 & 140 & 230 & $\mathrm{P}$ & $\mathrm{P}$ \\
B1PUI2 & 135 & 232 & $\mathrm{P}$ & $\mathrm{P}$ \\
B2PUI2 & 130 & 227 & $\mathrm{P}$ & $\mathrm{P}$ \\
B3PUI2 & 125 & 222 & $\mathrm{P}$ & $\mathrm{P}$ \\
B1PUT1 & 60 & 120 & $\mathrm{P}$ & $\mathrm{P}$ \\
B2PUT1 & 55 & 115 & $\mathrm{P}$ & $\mathrm{P}$ \\
B3PUT1 & 50 & 110 & $\mathrm{P}$ & $\mathrm{F}$ \\
B1PUT2 & 55 & 80 & $\mathrm{P}$ & $\mathrm{P}$ \\
B2PUT2 & 50 & 75 & $\mathrm{P}$ & $\mathrm{P}$ \\
B3PUT2 & 45 & 70 & $\mathrm{P}$ & $\mathrm{F}$ \\
\hline
\end{tabular}

\section{Flexibility (ASTM D 622)}

$P=$ Pass, $F=$ Fail

For the determination of flexibility, mild steel panels were used. The coating compositions were applied and cured in the same manner as mentioned above. Flexibility test were carried out using mandrels having specific rod diameter. Generally 1/8 inch rod diameter mandrel was used and if film passed through 1/8 inch mandrel then it was said to be passed for the flexibility test. The results are given in Table 3 .

\section{Scratch hardness}

In this method, a hand operated instrument was used in which test panel was kept on a sliding base with coated side upward and scratched under specific load with a needle which was in contact with film on test panel. The load was kept increasing till the film was scratched which was indicated by a light bulb that glows when film was scratched. The results are given in Table 4.

\section{Pencil hardness}

In this method the use of pencil having different hardness are used. Sharp tipped pencils having hardness $4 \mathrm{~B}$ (soft) and $6 \mathrm{H}$ (hard) were used to scratch the film. The pencil was held approximately at an angle of $45^{\circ}$ to the film and with uniform pressure pulled down over the length of the film. The test was repeated till a pencil with specific hardness was able to scratch the film and hardness off that pencil was reported as the pencil hardness test. The results are given in Table 4.

\section{Impact resistance (ASTM D 2794)}

The coated test panels for impact resistance test were prepared in the same manner as described above. The test was carried out after 168 hour of coating application. The coated panel was kept 
on a platform (coated side upward). The panel was then indented with an object of specific weight from the varying heights. The test was repeated by increasing the height from which the object falls till the film was cracked or detached. The results are given in Table 4 .

Table 4. Mechanical properties of PU cured coating from (RPR-CO) blends with TDI and IPDI

\begin{tabular}{cccc}
\hline $\begin{array}{c}\text { Polyurethane } \\
\text { code }\end{array}$ & Scratch hardness in g. & Pencil hardness & $\begin{array}{c}\text { Impact resistance } \\
\text { in·llb }\end{array}$ \\
\hline B1PUI1 & 1425 & $2 \mathrm{H}$ & 135 \\
B2PUI1 & 1630 & $3 \mathrm{H}$ & 155 \\
B3PUI1 & 1835 & $3 \mathrm{H}$ & 185 \\
B1PUI2 & 1440 & $2 \mathrm{H}$ & 145 \\
B2PUI2 & 1645 & $3 \mathrm{H}$ & 164 \\
B3PUI2 & 1855 & $3 \mathrm{H}$ & 225 \\
B1PUT1 & 2245 & $3 \mathrm{H}$ & 155 \\
B2PUT1 & 2425 & $3 \mathrm{H}$ & 170 \\
B3PUT1 & 2635 & $4 \mathrm{H}$ & 228 \\
B1PUT2 & 2295 & $3 \mathrm{H}$ & 159 \\
B2PUT2 & 2464 & $4 \mathrm{H}$ & 185 \\
B3PUT2 & 2685 & $4 \mathrm{H}$ & 235 \\
\hline
\end{tabular}

Determination of chemical resistance properties (ASTMD 1308)

The assessment of chemical resistance of the films to various chemicals, mild steel panels were used which were prepared, coated and cured as mentioned above. The immersion method was utilized to assess the chemical resistance of films in which the panels were immersed vertically in the baths containing solutions of different chemicals with specific concentration at room temperature for the specific time period. Upon completion of the specified time period the panels were removed from the baths and allowed to dry before visual examination. The results of resistance against chemicals are given in Table 5.

Table 5. Chemical Properties of PU curd coating from (RPR-CO) blends with TDI and IPDI

\begin{tabular}{cccc}
\hline $\begin{array}{c}\text { Polyurethane } \\
\text { code }\end{array}$ & $\begin{array}{c}\text { Acid resistance } \\
5 \% \text { HCl } 24 \mathrm{~h}\end{array}$ & $\begin{array}{c}\text { Alkali resistance 3\% } \\
\text { NaOH 2 h }\end{array}$ & $\begin{array}{c}\text { Water resistance } \\
\text { (Dist. Water) } 168 \mathrm{~h}\end{array}$ \\
\hline B1PUI1 & 5 & 5 & 3 \\
B2PUI1 & 4 & 4 & 4 \\
B3PUI1 & 5 & 5 & 4 \\
B1PUI2 & 4 & 4 & 4 \\
B2PUI2 & 5 & 5 & 4 \\
B3PUI2 & 5 & 5 & 5 \\
B1PUT1 & 4 & 4 & 4 \\
B2PUT1 & 5 & 5 & 5 \\
B3PUT1 & 5 & 5 & 5 \\
B1PUT2 & 5 & 5 & 5 \\
B2PUT2 & 5 & 4 & 5 \\
B3PUT2 & 5 & 5 & 5 \\
\hline
\end{tabular}

$0=$ film completely removed, $3=$ loss in gloss, $1=$ film removed and particularly cracked, $4=$ slight loss in gloss, 2 = film partially cracked, 5 = film largely unaffected 


\section{IR spectral study of polyurethane products}

The IR spectrums of Polyurethane were scanned neat on $\mathrm{KBr}$ pellets. The IR spectrum of IPDI and TDI are shown in Figure 1 and Figure 2. The spectra shows informative results in order to confirm the presence of certain functional groups required for reacting with aromatic diisocyanate for formulating polyurethanes. In all above spectra, the $-\mathrm{N}-\mathrm{H}$ stretching and bending vibration of urethane linkage is observed at $3479 \mathrm{~cm}^{-1}$ and $1535 \mathrm{~cm}^{-1}$ respectively. In the spectrum, bands at $2862 \mathrm{~cm}^{-1}$ and $1450 \mathrm{~cm}^{-1}$ are observed due to $-\mathrm{C}-\mathrm{H}$ stretching vibration of alkane chain in the oil. The sharp bands at $1705 \mathrm{~cm}^{-1}$ reveal the presence of ester group. The unsaturation present in each can be clearly seen by the sharp $\mathrm{C}=\mathrm{C}$ - stretching absorption at $1640 \mathrm{~cm}^{-1}$ as well as by out of plane $=\mathrm{C}-\mathrm{H}$ bending vibration at $900 \mathrm{~cm}^{-1}$ and $1010 \mathrm{~cm}^{-1}$. The additional band at $787 \mathrm{~cm}^{-1}$ confirms the presence of double bonds $(-\mathrm{C}=\mathrm{CH}-)$. The disappearance of the band at this frequency region is the evidence for the extent of curing.

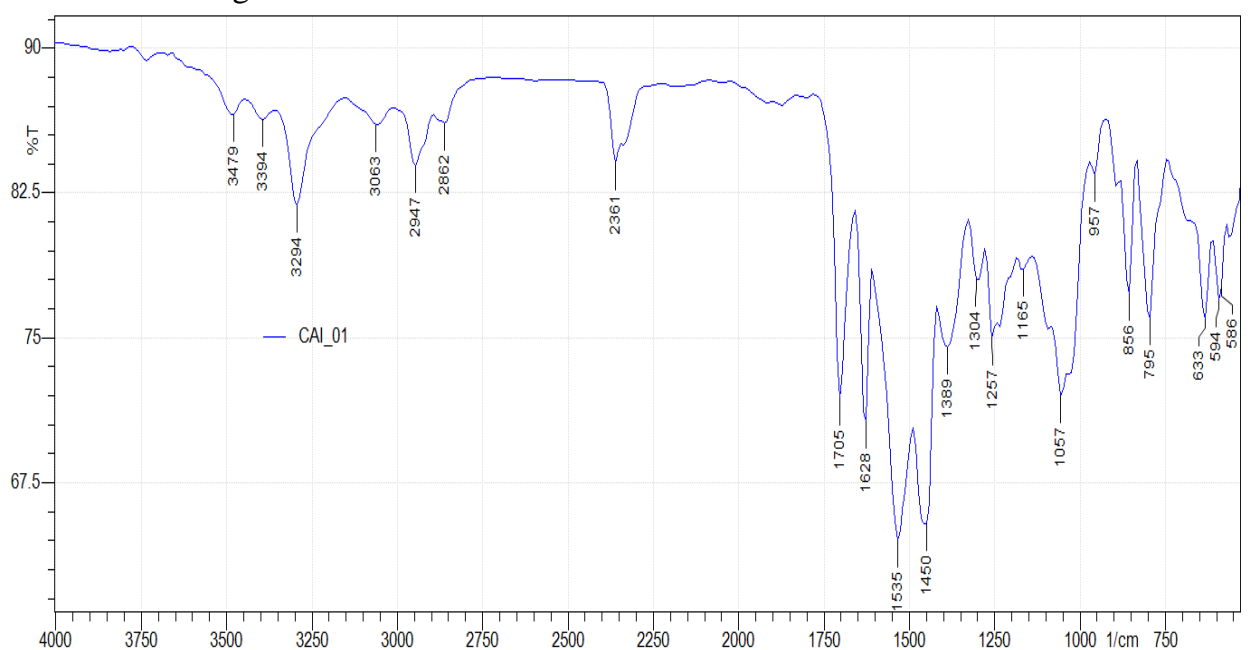

Figure 1. IR Spectra of Polyurethane from IPDI

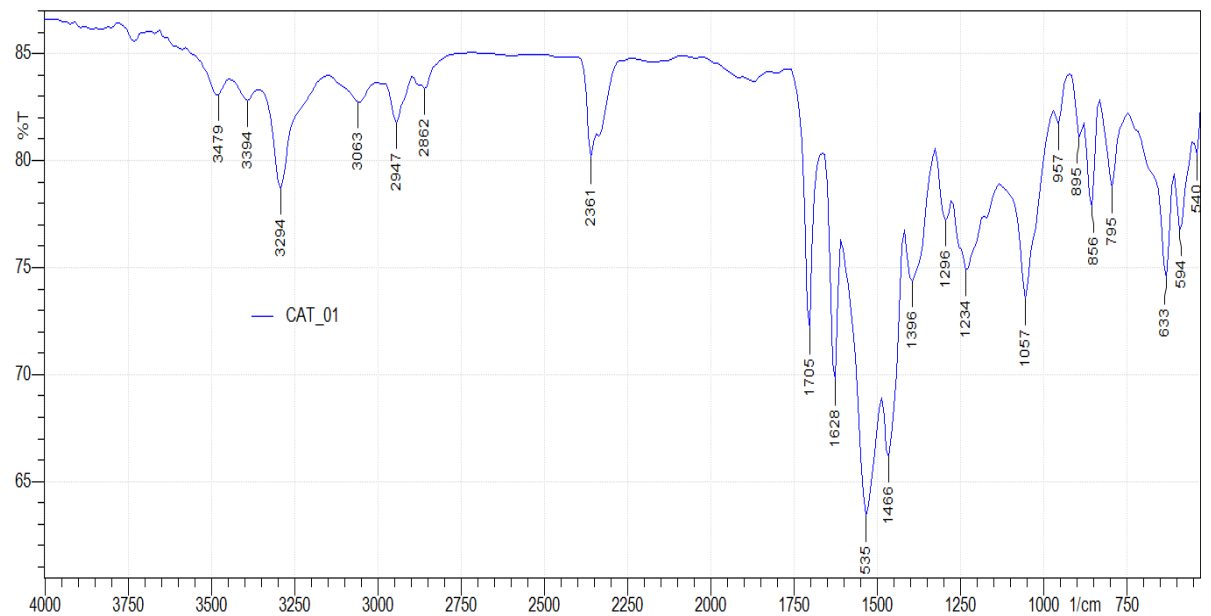

Figure 2. IR Spectra of Polyurethane from TDI 


\section{Conclusion}

Room temperature curing composition can be prepared easily and give satisfactory results. Drying time of films based on TDI shows faster drying than compared to PU films based on IPDI. PU films based on TDI shows improved scratch hardness than PU films based on IPDI. Also results of scratch hardness, pencil hardness and resistance against chemicals are higher in case of PU films prepared from TDI as compared with PU films prepared from IPDI.

\section{Acknowledgement}

The authors thankful to Head of the Department, for providing research facilities.

\section{References}

1. Wang F Y, Chen C M and Wu W J, J Appl Polym Sci., 2001, 80(2), 188-196; DOI:10.1002/1097-4628(20010411)80:2<188::AID-APP1086>3.0.CO;2-B

2. $\quad$ Chen C M, Seng H T and Wu H D, J Appl Polym Sci., 1998, 69(6), 1119-1127; DOI:10.1002/(SICI)1097-4628(19980808)69:6<1119::AID-APP9>3.0.CO;2-J

3. Vashish U, Rani G, Ali V, Kaushal J. Alam T, Alhadi S A and Mohd I, J Chem Chem Eng., 2011, 738-746.

4. Mohapatra D K, Nayak P L and Lenka S, J Polym Sci Part A: Polym Chem., 1997, 35(15), 3117-3124;

DOI:10.1002/(SICI)1099-0518(19971115)35:15<3117::AID-POLA4>3.0.CO;2-T

5. Yokoyama N, J Appl Polym Sci., 2006, 102(3), 2099-2106; DOI:10.1002/app.24094

6. $\quad$ Gotfryd A Z, Prog Org Coat., 2004, 49(2), 109-114;

DOI:10.1016/j.porgcoat.2003.09.002

7. Mishra D K, Mishra B K, Lenka S and Nayak P L, Polym Eng Sci., 1996, 36(8), 1047-1051; DOI:10.1002/pen.10493

8. Jang S, US 3,776,869, 1973.

9. Lin J, Wang W, Wen X, Zhi-Qi Cai, Zheng D F, Cheng J and Yang Z, Pigment Resin Technol.,, 2012, 41(6), 351-358; DOI:10.1108/03699421211274270

10. Kattimuttathu S I and Vadi K S, Ind Eng Chem Res., 2005, 44(13), 4504-4512; DOI:10.1021/ie0488750

11. Kothandaraman H and Sultan N A, J Molecular Sci., Part A:Pure and Appl Chem., 1995,32(5), 1017-1024; DOI:10.1080/10601329508009344

12. Gopalakrishnan S and Linda F T, J Chem Pharm Res., 2011, 3(2), 848-862.

13. Subrayan P, Zhang S, Jones F N, Swarup V and Yezrielev A I, J Appl Polym Sci., 2000, 77(10), 2212-2228;

DOI:10.1002/1097-4628(20000906)77:10<2212::AID-APP15>3.0.CO;2-B

14. Gopalakrishnan S and Linda F T, J Chem Pharm Res., 2011, 3(2), 848- 862.

15. Patel B K, Patel H S and Desai S N, Der Chemica Sinica, 2012, 3(5), 1052-1057.

16. Yuan H, Xing W, Yang H, Song L, Hu Y and Yeoh H G, Polymer International, 2012.

17. Knop A and Scheib W, Springer- Verlag Berlin Heidelberg New York, 1979.

18. Naughton F C, J Oil Color Chemists Assoc., 1974, 51, 65.

19. Achaya K T, J Oil Color Chemists Assoc., 1971, 48, 759.

20. Lakshminarayana G, J Oil Technol Assoc India, 1981, 13, 75.

21. Lakshminarayana G, Paulose M M, Vishwanadham B, Laxminarayana J and

Ramalingaswamy P A, J Am Oil Chem Soc., 1991, 68(3), 179-192;

DOI:10.1007/BF02657765

22. Chandra S and Gupta R K, Pigment Resin Technol., 1994, 23(1), 7-9;

DOI:10.1108/eb043097 
23. Potter T A, Schmelzer H G and Baker R D, Prog Org Coat., 1984, 12(4), 321-338;

24. Patel B M and Patel H S, Der Chemica Sinica., 2014, 5(1), 119-123.

25. Patel H S, Patel B K, Patel K B and Desai S N, Int J Poly Mater., 2009, 59(1), 25-32;

DOI:10.1080/00914030903172882 